\title{
Author Correction: Eight problems with literature reviews and how to fix them
}

Neal R. Haddaway (1), Alison Bethel, Lynn V. Dicks, Julia Koricheva (1D, Biljana Macura (1), Gillian Petrokofsky, Andrew S. Pullin, Sini Savilaakso (D) and Gavin B. Stewart (D)

Correction to: Nature Ecology \& Evolution https://doi.org/10.1038/s41559-020-01295-x, published online 12 October 2020.

In the version of this Perspective originally published, the affiliation listed for Biljana Macura, 'Mercator Research Institute on Climate Change and Global Commons, Berlin, Germany', was incorrect and should have been 'Stockholm Environment Institute, Stockholm, Sweden'. This has now been corrected.

Published online: 19 October 2020

https://doi.org/10.1038/s41559-020-01346-3

(c) Springer Nature Limited 2020 